\title{
Balancing Tenure Requirements with Family Life: Perspectives from Three Tenure-Track Faculty Members
}

\author{
Jay R. Porter, Rainer Fink, James Ochoa \\ Texas A\&M University
}

\begin{abstract}
Tenure track faculty members often find that the tenure process is very time consuming. This means that the successful tenure-track faculty member must find ways of balancing one's career with one's personal life. This paper presents perspectives for three new faculty members currently going through the tenure process at Texas A\&M University. It concludes by summarizing some of the common issues facing new faculty and proposing solutions.
\end{abstract}

\section{Introduction}

As a new faculty member begins a career in a research-oriented university, the first goal must be to gain tenure. This is typically a five to six year process that is very rigorous and is completed by demonstrating success in three main areas. At Texas A\&M University (as with most major universities), these requirements include [1]:

- Research: The foremost priority in the tenure process is demonstrating the ability to perform externally funded research. This translates into tenure-track faculty spending a majority of their time making research-related contacts, attending conferences, writing proposals, managing contracts and students, staying current through personal research, and writing papers.

- Teaching: Equally as important as becoming a successful researcher is demonstrating excellence in the area of teaching. For a new faculty member, this translates into developing new course material, teaching courses, managing teaching assistants, and seeing students outside of class. In the department discussed here, a full teaching load is three courses each semester and, in addition, new faculty must assume the responsibility of advising twenty to forty undergraduate students.

- Service and Professional Development: Finally, a tenure-track faculty member must perform university and professional service such as reviewing external materials, serving on departmental and university committees, and serving on national and international organization committees.

Because of these numerous objectives, the tenure process can require much of a new faculty's available time and attention. Indeed, it has been stated that working forty hours a week is not sufficient when pursuing tenure [2]. A study at the University of Idaho shows that the typical faculty member works an average of sixty hours a week [3]. In addition to these work-related 
demands, the tenure-track faculty member also has personal commitments. In particular, new faculty with families must find creative solutions to balance work with the needs of the family. This paper presents different perspectives on balancing work and family life from three tenuretrack faculty members within Engineering Technology and Industrial Distribution Department at Texas A\&M University. While the personal circumstances for each faculty member are unique, they all share the common goal of placing first priority on family life.

\section{Faculty Perspectives}

Faculty \#1 - The first faculty member is 36 years old and graduated with a Ph.D. in 1993. After working as a post-doctoral student for three years, he joined a smaller university where he worked as a tenure track faculty member for three years. He then joined Engineering Technology and Industrial Distribution Department at Texas A\&M University in 1998. He has been married for twelve years and has three children who range in age from two to seven years of age. His wife remains at home full time to raise the children:

"First, I would like to give some background on my situation. I have been a faculty member in the Engineering Technology and Industrial Distribution Department at Texas A\&M University for just over two years. Prior to joining A\&M I was a tenure-track faculty member at a small university in Texas. While I worked very hard in my previous position, I was one of few tenure-track faculty members in the whole college and so I felt very little competition. Also, the school was just making the change from being an all-teaching university to a research university so any contribution I made in the area of research felt very important. From a teaching standpoint I taught three to four separate courses a semester. Because I feel that the teaching is the most important aspect of my job, I maintained an open door policy with the students and spent whatever time was necessary to ensure the highest level of quality in my courses.

When the opportunity to work at a much larger school became available, I immediately accepted. One of my first perceptions about working at A\&M was a large increase in the level of pressure to perform over my previous job. While the spoken requirements for tenure were very similar to my previous position, a quick survey of other tenure-track faculty members suggested that I would need to spend a lot more time at work. Also, I felt that it was very important to be involved, so whenever a senior faculty member approached me to participate in a project, I did. I quickly found myself spread very thin trying to keep up with teaching, student advising, and all of my research interests and commitments. This led to many late evenings in the office and usually spending between sixty to eighty hours a week at my job. When I was not at work, I was usually thinking about it at home.

Fortunately, before I accepted the position my wife and I had discussed my career and we had agreed that I would spend any time necessary to be successful. In retrospect, this was very important since it led to us having the same perception about my job. However, while the workload did not create problems between my wife and myself, it did leave me with a personally 
dissatisfied feeling about both my job and my home life. It is my personal feeling that my family should be my first priority, and at that point I felt that I was not meeting that goal. Also, even though I was receiving very positive evaluations from the students, I felt like my teaching was not where I wanted it to be.

About that time, I was awarded a fairly substantial project and it helped immensely to reduce the pressure I was feeling. I also sought advice from some of the senior faculty members and it helped convince me that I needed to change the way I was handling my work. I now have learned to say no more often to tasks that are not taking me in a direction that will help me gain tenure. As senior faculty members have pointed out, there will be time to digress after receiving tenure. I also recently attended a lecture on the tenure-track process. While I found that I did not understand the tenure requirements as well as I originally thought, it has helped me realign my immediate priorities. I only wish I had done this sooner. I am learning to manage a group better and to delegate work when it is appropriate. I still maintain an open door policy with the students, but, when I need to get work done, I try to stay in the lab. I also try not to get sidetracked as much (it is very easy to spend large portions of the day talking to colleagues) so that I can finish the tasks I set for myself each day.

As a result, I am able to spend more quality time at home. While I still work long hours, when I am at home I can concentrate on my family. I also recognize that the tenure process is finite and while the amount of work I have to do will stay the same or increase, the pressure will get better. This has all helped to create a much more satisfactory feeling about my job and myself."

Faculty \#2 - The second faculty member is 33 years old and graduated with a Ph.D. in Electrical Engineering in 1998. Prior to graduating, he worked concurrently as a lecturer in Engineering Technology and as an assistant research engineer for the Texas Transportation Institute (TTI). He has been married seven years and has three children. His wife also stays at home to raise the children:

"At a major university like Texas A\&M, gaining tenure is far from a trivial challenge. With this in mind, I regularly find myself striving to get more and more done. Specifically, I actively pursue new research opportunities, expand the material covered in the courses I teach, and continually increase my role in service and social activities. Certainly this is no different from other faculty members.

My position with the university is a bit different from other members of the electronics engineering technology (EET) faculty in that I spend 50\% of my time as a researcher for the Texas Transportation Institute. My work at TTI directly relates to the courses I teach and to research efforts I pursue in the EET Program. Nevertheless, this arrangement of working under two organizations requires considerable time and care in managing.

Although I have been on a tenure track for only 15 months, my professional and personal life has 
changed dramatically since joining the faculty. I like my job! I became a faculty member for a number of reasons including academic freedom, my joy of teaching young energetic engineers, and the flexibility to spend my summers wherever I choose (e.g., working with industry, traveling abroad, etc). In fact it is this fondness of my job that allows me to often work 12-hour (and sometimes 16-hour) days.

However, the compromises that this level of work effort has required go against the personal priorities that I proclaim. When asked my priorities, I quickly respond with "religion, family, and health" as my most important ones. I am married with three young children. My wife and I enjoy travel and spending time with our children and other family. Over the last 15 months, however, these priorities have been pushed aside as I build my credentials toward gaining tenure. Clearly, a balance is needed between my dedication to success in the tenure process and my personal priorities. My plan at this point is to develop a well-defined strategy for meeting the tenure-track expectations (without an unusual level of compromise of the time with my family). While I have not yet developed my strategy, there are some obvious elements to include in the plan.

First, it will be useful to identify those factors that most influence my workload with the idea of reducing this load to something reasonable. Because I currently juggle several distinct researchrelated initiatives, each of which demand much time, I find myself being pulled in different directions. Recently, though, one of these initiatives became significantly more important than the rest. Thus, I am inclined to focus the bulk of my attention on this initiative and bring the others (or at least most of the others) to a close. Second, the tenure-track faculty in my college recently attended a seminar that addressed university tenure requirements. As a personal outcome, I have a clearer picture of where to place my energies in order to maximize my strengths and minimize weaknesses. Based on this, I plan to document a strategy for meeting the tenure requirements. This too will help optimize the time I spend at work. Third, I plan to reduce the frequency of staying at work late. With three young children at home, when I am at work late, she is "at work" late, too. The truth of the matter is I do want to be at home with my family in the early evening. Even with the tenure process ending for me in about four or five years, my children are growing up quickly now! Dramatic as this view may be, it is reality. I am very optimistic that success in the above two strategies will allow me to regain my practice of the priorities I proclaim -- family first."

Faculty \#3 - The third faculty member is 35 years old and graduated with a Ph.D. in Biomedical Engineering from Texas A\&M University in 1995. He worked concurrently as a lecturer in the Biomedical Engineering Program and Electronics Engineering Technology for one semester before beginning his tenure track in 1996. He has been married for 5 years and has a one year old son. He wife also has earned the Ph.D. degree in Electrical Engineering and the medical degree (MD) from the Baylor College of Medicine and is currently a third year radiology resident with the University of Texas Medical System in Houston:

"My perspective on tenure is unusual from many viewpoints, both from the family life perspective 
and also from my viewpoints on the requirements for tenure. My family life can only be categorized as chaotic. With a wife that is as career driven as I am and two very time consuming careers, the time issue becomes very critical. When my wife and I were married, we knew we were up for some really tough years - my tenure track years and the time required for her to complete a Ph. D. and MD along with seven years of residency. We were both committed to having two children in our family, which also required extensive timing.

It turns out there are good times and bad times during a residency to have children. We were lucky and our son was born just after Christmas (vacation time) last year. Although having a child is a very wonderful experience, it can be very time consuming and distracting. Our current schedule is a balancing act between who will be home each night and when will we all be home for some quality time. We are very careful that one of us is home to be with our son every night. During the day we have a full time nanny that takes great care of him. I have adopted the following philosophy - family comes first without question!! This means that whenever I am at home and my wife and son are awake, I will spend the time with my family. When they are asleep I get my work done. This leaves very long nights and sections of time when they are both napping to get my work completed.

Although time is a major issue, another major challenge faces me every day. Since my wife's job is in Houston and mine is in College Station, I commute to work every day. The daily drive is approximately 70 miles each way and takes approximately one hour. Although this sounds like a terrible burden, I have found that the morning drive gives me a chance to plan the day and the evening drive gives me a chance to wind down before getting home. Thus I'm ready to work when I get to the office and I leave the troubles of the day behind me on the way home. My perspective on tenure is a very unique one. I believe that as long as I am performing at the limit of my capability, I will be judged on the merits of my performance. If I obtain tenure, then my best was good enough. If tenure is denied me, then I am not qualified to instruct students despite my best effort and I may be better placed in an industry position. With today's industry and the manpower shortage, I am convinced I would be able to obtain another position rather quickly. Thus I understand the general requirements that are placed on tenure, but I will not sacrifice my family life to obtain tenure."

\section{Common Threads}

While these faculty members have fairly distinct circumstances, examining their experiences demonstrate that one of the most important issues that new faculty have to face is learning how to save time at work so they can spend it with the family. Learning to work efficiently can be accomplished through several mechanisms that include finding out what is expected, developing time management skills, learning to focus, and defining the line between work and home. The following summary attempts to clarify these issues and present potential solutions:

- Understanding the Job: Faculty \#1 and \#2 indicated that finding out more about the tenure 
process was instrumental in setting priorities. In fact, good education can help prevent new faculty from wasting time and experiencing unnecessary stress [4]. This education can come in a variety of forms. For example, most universities distribute information on the tenure process. By understand the tenure requirements as soon as possible, new faculty can avoid wasting precious time on dead-end tasks. Teaching workshops are another educational opportunity that can lead to efficient use of time. Because most new faculty have very little experience teaching, investing time up front developing good teaching skills can pay off very rapidly. Also, finding and talking with a mentor who has been through the tenure process can help a tenure-track faculty member avoid costly mistakes. Finally, there are several good texts on the tenure process that can help new faculty members develop good perspectives $[5,6]$.

- Developing Time Management Skills: All three of the above faculty members have learned to recognize the importance of managing their time effectively. Making effective use of time at work means more time for the family. While there is no substitute for experience, there are texts that can give a new faculty member some hints on time management. One example is a text for new faculty written by Richard Reis from Stanford University that deals with this as well as other issues [5].

- Learning to Focus: Faculty \#1 and \#2 discuss the effect of pursuing multiple opportunities demonstrating that "Academic freedom" can be a double-edged sword. With the endless opportunities presented in an academic atmosphere, it is easy to become distracted. One should find his/her focus and pursue the opportunities that lead to this end. This requires learning to say no to yourself and others when it comes to time-consuming tasks that do not directly relate to your goals.

- Defining the Line Between Work and Home: Again all three faculty have indicated that they are still learning how define the line between work and home. An article by Margaret Newhouse [7] lends some valuable insights to this issue. Some of these insights include: discussing the implications of a career in academics with your spouse early in the tenure process to ensure that you both have the same concept of what lies ahead; setting defined boundaries between work and home (i.e. not bringing work home) so that time at home means quality time; deciding on your values from the beginning and sticking to them.

\section{Conclusion}

While it is ridiculous to suggest that there is a "one answer fits all" solution, the experiences of these faculty members suggest many new faculty face common problems when trying to balance a career and a family life. Most of these can be dealt with through time management, prioritization, and faculty education. Regardless of the solutions used by individual faculty, these issues should be dealt with sooner (at the outset of a tenure-track appointment) rather than later. Above all, new faculty should become informed about all aspects of the tenure process as early as possible, and make a plan to differentiate between their career and their home life. As Richard Reis states in a article in ASEE Prism [8], "It is a mistake for faculty members to sacrifice their relationships with family and friends for six years on the assumption that they can "catch up" after the magical

moment when they receive tenure. Starting out, faculty members should decide how they want to

Proceedings of the 2001 American Society for Engineering Education Annual Conference \& Exposition Copyright (O) 2001, American Society for Engineering Education 


\section{live their lives."}

Bibliography

1. Appointment, Promotion and Tenure Criteria for Faculty. Texas A\&M University College of Engineering, 1992.

2. Myers, P.S. Teaching versus Research - Incompatibility or Overemphasis? Journal of Engineering Education, January 1993, pp. 22-26.

3. URL: http://www.its.uidaho.edu/facultycouncil/documents.html, Report on Faculty Morale at the University of Idaho, Faculty Affairs Committee, University of Idaho.

4. URL: http://gseweb.harvard.edu/ hpfa/torture.htm, Alleviating the Torture of the Tenure Track: All it takes is a Little Show and Tell. The Project on Faculty Appointments at Harvard University.

5. Reis, R.M., Tomorrow's Professor: Preparing for Academic Careers in Science and Engineering. IEEE Press (1997).

6. Whicker, M.L., Kronenfeld, J.J., Strickland, R.A. Getting Tenure. Thousand Oaks, CA: Sage Publications, Inc. (1993).

7. URL: http://chronicle.com/jobs/99/11/99110501c.htm, Finding a Balance Between Family and Work. Career Network, The Chronicle of Higher Education.

8. Reis, R.M., "The Tenure Journey," ASEE Prism, March 1997, p.20-24.

\section{JAY PORTER}

Jay R. Porter joined the Engineering Technology program at Texas A\&M University in 1998 as an Assistant Professor and currently works in the areas of mixed-signal circuit testing and virtual instrumentation development. He received the BS degree in electrical engineering (1987), the MS degree in physics (1989), and the Ph.D. in electrical engineering (1993) from Texas A\&M University.

\section{RAINER FINK}

Rainer Fink received the BS degree in biomedical engineering (1988), the MS degree in biomedical engineering (1992), and the Ph.D. in biomedical engineering (1995) from Texas A\&M University. After finishing his Ph.D., he was a lecturer in the Bioengineering Program and the Department of Engineering Technology at Texas A\&M University. In August 1996, he joined the Electronics Engineering Technology faculty at Texas A\&M University. His research activities include mixed-signal testing, analog circuit design and biomedical electronics.

\section{JAMES OCHOA}

James Ochoa received a BS degree in electrical engineering at Texas A\&M University - Kingsville in 1990 and a $\mathrm{Ph} . D$. in electrical engineering at Texas A\&M University in 1999. After completing his Ph.D., he joined the faculty in the Department of Engineering Technology at Texas A\&M University. His research activities include digital circuit testing, system-on-a-programmable-chip, and control systems. 